\title{
Clinical and microbiological profile of health care associated pneumonia in patients with chronic renal disease referred to a tertiary care hospital- a prospective study
}

\author{
Rao C.M. ${ }^{1}$, Subhankar S. ${ }^{2}$, Patnaik A.P. ${ }^{3}$, Dash D.P. ${ }^{4}$ \\ ${ }^{1}$ Dr. C. Mohan Rao, Assistant Professor, Department of Respiratory Medicine, ${ }^{2}$ Dr. Saswat Subhankar, Assistant Professor, \\ Department of Respiratory Medicine, ${ }^{3}$ Dr. Aswini Prasad Patnaik, Sr Consultant, Department of Nephrology, ${ }^{4}$ Prof Debee \\ Prasad Dash, Professor and HOD, Department of Respiratory Medicine, Kalinga Institute of Medical Sciences, KIIT \\ deemed-to-be-University, Bhubaneswar, Odisha.
}

Corresponding Author: Dr. Saswat Subhankar, Assistant Professor, Department of Respiratory Medicine, Kalinga Institute of Medical Sciences, KIIT deemed-to-be University, Bhubaneswar, India. E-mail: saswat.kmc04@gmail.com

\begin{abstract}
Background: Healthcare associated pneumonia (HCAP) is a public health problem in the era of home care of chronic illness including chronic renal disease. They have greater burden of comorbidities, immune suppression and impaired mobility. Aim of the Study: To characterise the clinical, radiological and microbiological profile of health care associated pneumonia in chronic renal disease cases including its resistance pattern and outcome in the study population. Materials and Methods: This prospective study was conducted among patients with chronic kidney disease (CKD) who had been treated in multiple hospitals across Odisha. They were subjected to history taking, clinical examination, laboratory and radiological investigations. Sputum or endotracheal tube culture were sent for gram stain and aerobic culture. All the categorical parameters were compared using Fisher's exact test. Continuous parameters were compared using independent t-test. All the statistical analysis was carried out using the software Stata 15.1. A p-value less than 0.05 was considered significant. Results: 58 patients with an underlying chronic kidney disease were included. $54(93.1 \% \%)$ patients survived while $4(6.9 \%)$ died. The mean age, total leucocyte count and serum urea levels were higher among patients who died in comparison to the survivors ( $\mathrm{p}=0.95,0.334$ and 0.386 respectively). Klebsiella spp (12.07\%), and Acinetobacter (8.6\%) were most commonly isolated. Multi-drug resistance (MDR) and extensive drug resistance (XDR) were encountered among these organisms. Death was more commonly associated in patients $\geq 60 \mathrm{yrs}(p=1)$, TLC $\geq 11000$ cells $/ \mathrm{mm} 3(p=0.0091)$, serum creatinine $\geq 3 \mathrm{mg} / \mathrm{dl}(\mathrm{p}=0.329)$ and radiological involvement of $\geq 3$ zones $(p=1)$. Conclusion: CKD is an important contributor in HCAP. Data from different institutions to corroborate our findings regarding antibiotic resistance pattern of the microbes in HCAP cases is recommended.
\end{abstract}

Keywords: HCAP, Klebsiella spp, Acinetobacter, MDR, XDR.

\section{Introduction}

Chronic kidney disease is a huge public health problem and currently awareness of treatment by dialysis and transplantation is also increasing. The essential criteria refined by Kidney Disease Improving Outcomes (KDIGO) in 2012 stipulates as follows-

a. Evidence of chronic kidney damage

i- Persistent proteinuria and or abnormal urinary sediment

ii- Structural abnormalities (identified on imaging)

iii- Abnormalities in renal histology

iv- Low GFR (less than $60 \mathrm{ml} / \mathrm{min}$ )

Manuscript received: $20^{\text {th }}$ August 2019

Reviewed: $30^{\text {th }}$ August 2019

Author Corrected: $5^{\text {th }}$ September 2019

Accepted for Publication: $7^{\text {th }}$ September 2019 v- Presence of either of these criteria for a period of at least 3 months OR Renal allograft recipient with or without low GFR.

Using this definition, the Global Burden of Kidney study 2015 has identified CKD as the most common noncommunicable disease in the world and a leading cause of mortality.

The global prevalence of CKD is reported as $13.4 \%$ [1] and in India 17\% respectively [2]. The expenditure on medical care is about 48.1 billion us dollars in USA. The incidence of diabetes, a major cause of CKD is on the rise as also the average life span of population. As diabetes is increasing in the developed and developing 
Original Research Article

countries like a silent epidemic, so is CKD. Respiratory infection is an important component of uremic symptoms. The cause of pneumonia has been changing for decades in response to a multitude of such factors such as age, chronic illness, frequency of empirical antibiotic therapy and the emergence of new pathogens.

The 2005 update on the treatment of nosocomial pneumonias, the American Thoracic Society and Infectious Diseases Society of America includes health care- associated pneumonia as a separate category in a set of risks including chronic kidney disease patients on maintenance [3].

Increased population of immunosuppressed patients, device associated infections, instrumentation which are often needlessly applied, colonisation on hands of health care workers and irrational antibiotic therapy in Indian hospitals are contributory factors of the changes in epidemiology of antimicrobial resistance and increased vulnerability for nosocomial infections. However, a well-designed good study on healthcare associated pulmonary infection associated with chronic renal disease in India is infrequently reported.

Determining the regional etiology of HCAP is essential for optimising therapy outcome while minimising unnecessary broad-spectrum antimicrobial use.

The emergence of multidrug resistance among bacterial species is a worldwide public threat that is evolving at an alarming rate. Pathogens, including extended-spectrum beta- lactamase (ESBL) producing and carbapenemresistant Enterobacteriaceae (CRE), methicillinresistant Staphylococcus aureus (MRSA), Vancomycinresistant Enterococcus species and multidrug resistant Acinetobacterbaumanni pose an ongoing challenge and are associated with health care associated infections [4, 5].

European centre for disease control (ECDC) and Centre for Disease control \& prevention (CDC), Atlanta have defined multidrug resistant (MDR), extensive drug resistance (XDR) and pan drug resistant (PDR) bacteria among patients admitted in hospital acquired infection in ICU. Multidrug resistant bacteria are defined as acquired resistance to at least one agent in three or more antimicrobial categories. Extensively drug resistant is defined as bacterial isolate susceptible to only one or two antimicrobial categories. Pan drug resistance is defined as non-susceptibility to all agents in all antimicrobial categories. In the last decade, there has been a dramatic increase worldwide in the number of multidrug resistant Gram neg (MDRGN) bacterial pathogens.
Compared with CAP, HCAP patients have more severe disease, higher mortality, and increased length of hospital stay and greater cost of care.

\section{Materials and Methods}

Study design: It was a prospective cohort analysis of patients with chronic kidney disease (CKD) with symptoms and/or signs of pulmonary infection who had been treated in multiple hospitals across Odisha and adjoining West Bengal.

Study area: The study was conducted at Kalinga Institute of Medical Sciences (KIMS), Bhubaneswar, a tertiary care hospital. Thus, patients from nearby areas and adjoining districts were referred for treatment.

Study period: The study was conducted between November 2016 and October 2018.

Study population: The study included patients with chronic kidney disease (CKD) admitted to the nephrology ward, intensive care unit or pulmonary ward with symptoms and/or signs of pulmonary infection who had been treated in multiple hospitals across Odisha and adjoining West Bengal. A total of 58 patients were included in the study.

Inclusion criteria: All patients of CKD with a pneumonia and fulfilling the following criteria from 2005 IDSA/ATS guidelines along with a diagnosis of pneumonia were included in the study:

1. Hospitalisation for at least $48 \mathrm{hrs}$ in the preceding 90 days due to kidney disease with or without associated co morbidities if any.

2. Chronic dialysis within 30 days.

Pneumonia was defined as new/progressive radiographic infiltrate at presentation plus two or more of the following:

- Temperature of $>38$ degree $\mathrm{C}$ or $<36$ degree $\mathrm{C}$

- White blood cell count of more than 12000 or

$<4000 \mathrm{cells} / \mathrm{cu} \mathrm{mm}$ or

- New/ worsening respiratory symptoms.

\section{Exclusion criteria}

1.Patients with tuberculosis.

2. Patients with malignancy.

Procedure: All the eligible patients were subjected to detailed history taking, systemic examination, chest Xray and/or HRCT scan of thorax (when needed) to confirm pneumonia. Laboratory investigations including $\mathrm{CBC}$, sputum Gram stain and culture, ET aspirate if on 
ventilator and serum procalcitonin were performed before any antibiotics were administered. A written informed consent was obtained from all the patients/ attendants before inclusion in the study. The study was approved by the ethical committee of the institute.

Statistical methods: The data collected was clubbed in a single excel chart. All the categorical parameters were presented as frequency and percentage and compared

\section{Original Research Article}

between the two groups using Fisher's exact test. Continuous parameters were presented as mean $\pm \mathrm{SD}$ and compared between the two groups using independent $\mathrm{t}$ test. A p value of $<0.05$ was considered as statistically significant.

All the statistical analysis was carried out using the SPSS software Stata 15.1.

\section{Results}

58 patients with an underlying chronic kidney disease were included in the study. Majority of the patients belonged to the age group $>60$ years. The mean age among the patients with chronic kidney disease was $65.44 \pm 12.18$ years. The male to female ratio was 3.83:1 (Table 1).

Table-1: Demographic profile of the patients in the study.

\begin{tabular}{|l|c|}
\hline \multicolumn{1}{|c|}{ Demography } & Mean \\
\hline Age & 65.44 years $( \pm 12.18)$ \\
\hline$<45$ years & 3 \\
\hline $45-60$ years & 14 \\
\hline $61-75$ years & 29 \\
\hline$>75$ years & 12 \\
\hline M:F & $3.83: 1$ \\
\hline Patients on hemodialysis. & $27(46.55 \%)$ \\
\hline Patients on supportive therapy. & $31(53.45 \%)$ \\
\hline
\end{tabular}

Dyspnoea and cough $(79.3 \%$ and $77.6 \%$ respectively) were the most commonly reported symptoms among the CKD patients with HCAP. Only 17 (29.3\%) cases had fever (Table 2). The most common co-morbidity reports in the sub-group of patients was COPD (34.48\%) followed by cardio-vascular diseases and diabetes mellitus (25.86\% each). Majority of the patients $(65.5 \%)$ had a illness of less than 1 week.

Table 2: Symptoms and co-morbidities and duration of illness of the patients in the present study.

\begin{tabular}{|l|c|}
\hline Symptom & $\mathrm{n}(\%)$ \\
\hline Fever & $17(29.3 \%)$ \\
\hline Cough & $45(77.6 \%)$ \\
\hline Dyspnea & $46(79.3 \%)$ \\
\hline Extra-pulmonary symptoms & $15(25.86 \%)$ \\
\hline Co-Morbidities & \\
\hline COPD & $20(34.48 \%)$ \\
\hline Cardio-vascular diseases & $15(25.86 \%)$ \\
\hline DM & $15(25.86 \%)$ \\
\hline Neurological diseases & $1(1.7 \%)$ \\
\hline Malignancy & $2(3.4 \%)$ \\
\hline Others & $10(29.4 \%)$ \\
\hline Duration of illness & \\
\hline A. $<1$ week & $38(65.5 \%)$ \\
\hline B. $\geq 1$ week & $20(34.5 \%)$ \\
\hline
\end{tabular}




\section{Original Research Article}

Table 3 signifies $39(67.24 \%)$ cases had a normal total count $(<11000$ cells/mm3). The mean levels of serum urea $(96.61 \pm 42.91 \mathrm{mg} / \mathrm{dl})$ and creatinine $(3.846 \pm 2.235 \mathrm{mg} / \mathrm{dl})$, procalcitonin $13.42( \pm 18.63)$ were high.

Table 3: Total count and biochemical test of the patients in the present study.

\begin{tabular}{|l|c|}
\hline Total count $\left(\mathbf{c e l l s} / \mathbf{m m}^{\mathbf{3}}\right)$ & $\mathbf{n ~ ( \% )}$ \\
\hline$<11000$ & $39(67.24 \%)$ \\
\hline$\geq 11000$ & $19(32.75 \%)$ \\
\hline Biochemical Tests & Mean \\
\hline Hemoglobin & $9.33 \mathrm{mg} / \mathrm{dl}( \pm 2.17)$ \\
\hline S. Urea & $96.61 \mathrm{mg} / \mathrm{dl}( \pm 42.91)$ \\
\hline S. Creatinine & $3.846 / \mathrm{dl}( \pm 2.235)$ \\
\hline Total bilirubin & $0.916( \pm 1.7)$ \\
\hline Procalcitonin & $13.42( \pm 18.63)$ \\
\hline
\end{tabular}

Sample collection could be done from 38 (65.5\%) patients and the remaining 20(34.5.\%) cases were diagnosed on clinical and radiological grounds. Sputum was the most commonly collected specimen $(29.3 \%)$ followed by ET tube aspirate (18.97\%) and blood (17.24\%). Out of the 17 sputum samples collected, 8 (13.79\%) reported growth of organism while 9 (15.5\%) had no growth (sensitivity: $52.95 \%$ ).

Among the 11 ET tube aspirate specimens, 5 (8.6\%) showed growth while $6(10.3 \%)$ did not report any growth (sensitivity: $45.45 \%$ ). 5 blood culture samples reported growth (8.6\%) (sensitivity: 50\%) (Table 4).

Table-4: Results of samples collected (n-38)

\begin{tabular}{|c|c|c|c|c|c|c|c|}
\hline \multirow[t]{2}{*}{ Sample } & & \multicolumn{2}{|c|}{ Total (38) } & \multicolumn{2}{|c|}{$\begin{array}{c}\text { Positive } \\
18(31.03 \%)\end{array}$} & \multicolumn{2}{|c|}{$\begin{array}{c}\text { Negative } \\
20(34.48 \%)\end{array}$} \\
\hline & & ICU & Non-ICU & ICU & Non-ICU & ICU & Non-ICU \\
\hline Sputum & $17(29.3 \%)$ & 7 & 10 & 4 & 4 & 3 & 6 \\
\hline Et aspirate & $11(18.7 \%)$ & 11 & & 5 & - & 6 & - \\
\hline Blood & $10(17.24 \%)$ & 5 & 5 & 3 & 2 & 2 & 3 \\
\hline Total & 38 & 23 & 15 & 12 & 6 & 11 & 9 \\
\hline
\end{tabular}

Klebsiella spp (12.07\%) was the most common organism reported followed by Acinetobacter spp (8.6\%). This was followed by Pseudomonas (5.17\%) and E. coli (1.7\%). Resistance was reported among Klebsiella spp, Acinetobacter spp and Pseudomonas pathogens (Table 5).

Table-5: Organisms isolated and their sensitivity pattern (n-18).

\begin{tabular}{|l|c|c|c|c|c|c|c|c|c|}
\hline & Sensitive & & \multicolumn{2}{|c|}{ MDR } & \multicolumn{2}{|c|}{ XDR } & \multicolumn{2}{c|}{ PDR } & Total \\
\hline & ICU & Non-ICU & ICU & Non-ICU & ICU & Non-ICU & ICU & Non-ICU & \\
\hline E. coli & 1 & - & - & - & - & - & - & - & 1 \\
\hline Klebsiella & 2 & - & - & - & - & 4 & 1 & - & 7 \\
\hline Pseudomonas & 1 & - & - & - & 1 & 1 & - & - & 3 \\
\hline Acenito-bacter & 2 & - & 3 & - & - & - & - & - & 5 \\
\hline $\begin{array}{l}\text { (Fungus, } \\
\text { pneumocystis } \\
\text { jiroveci) }\end{array}$ & 1 & 1 & - & - & - & - & - & - & 2 \\
\hline Total & $\mathbf{7}$ & $\mathbf{1}$ & $\mathbf{3}$ & - & $\mathbf{1}$ & $\mathbf{5}$ & $\mathbf{1}$ & - & $\mathbf{1 8}$ \\
\hline
\end{tabular}


Table-6: Distribution of organisms in clinical specimens (n-18).

Original Research Article

\begin{tabular}{|l|c|c|c|c|c|}
\hline & E. coli & Klebsiella & Pseudomonas & Acinetobacter & Others \\
\hline Sputum & - & 6 & - & 1 & 1 \\
\hline ET aspirate & 1 & - & 2 & 2 & - \\
\hline Blood & - & 1 & 1 & - & 1 \\
\hline Urine & - & - & - & - \\
\hline
\end{tabular}

Out of the total of 58 cases, 54 survived and 4 died. Death was commonly observed in patients with age $\geq 60$ years ( $p=$ $1.0)$, TLC $\geq 11000$ cells $/ \mathrm{mm} 3$ ( $p=0.0091)$, serum creatinine $\geq 3 \mathrm{mg} / \mathrm{dl}(\mathrm{p}=0.3292)$ and radiological involvement of $\geq 3$ zones $(\mathrm{p}=1.0)($ Table 7$)$.

Table-7: Mortality profile of the patients from the present study.

\begin{tabular}{|c|c|c|c|}
\hline Age & Survivors & Deaths & $\mathbf{P}$ \\
\hline$<60$ years & 13 & 1 & \multirow[b]{2}{*}{$\mathrm{p}=1.00$} \\
\hline$\geq 60$ years & 41 & 3 & \\
\hline \multicolumn{4}{|l|}{ Gender } \\
\hline Male & 44 & 2 & \multirow[b]{2}{*}{$\mathrm{p}=0.186$} \\
\hline Female & 10 & 2 & \\
\hline \multicolumn{4}{|c|}{ TLC (cells/mm $\left.\mathbf{m m}^{3}\right)$} \\
\hline$<11000$ & 39 & 0 & \multirow[b]{2}{*}{$\mathrm{p}=0.0091$} \\
\hline$\geq 11000$ & 15 & 4 & \\
\hline \multicolumn{4}{|c|}{ S. creatinine $(\mathrm{mg} / \mathrm{dl})$} \\
\hline$<3$ & 30 & 1 & \multirow[b]{2}{*}{$\mathrm{p}=0.3292$} \\
\hline$\geq 3$ & 24 & 3 & \\
\hline \multicolumn{4}{|c|}{$\begin{array}{l}\text { Radiological involvement } \\
\text { (zones) }\end{array}$} \\
\hline$<3$ & 18 & 1 & \\
\hline$\geq 3$ & 36 & 3 & $\mathrm{p}=1.00$ \\
\hline
\end{tabular}

\section{Discussion}

The purpose of the study was to find out the etiology of health care associated pulmonary infection in CKD patients in our hospital and to elucidate their clinical, laboratory, radiological profile and further to identify microbiological etiology. A conscious and careful effort was made to find out incidence of drug resistance and outcome of therapy. Further attempt was made to find out the pattern of risk factors, incidence of healthcare pneumonia who supposedly did not show any pulmonary symptoms.

This prospective study shows that these patients had developed pulmonary infection after contact with health care system before being admitted to our hospital. They were vulnerable to subsequent pulmonary infection; the source of the infection could be ventilators, haemodialysis, device associated or from healthcare personnel. The appropriateness of antibiotic therapy may not be effective in all cases [6].

Out of 58 cases having chronic kidney disease 27 were on haemodialysis. Haemodialysis status in our series (46.55\%) may be associated with recent hospitalisation, nursing home residence that may have contributed to risk of HCAP. Two large retrospective studies showed high disease burden and mortality of pneumonia in haemodialysis patients $[7,8]$. This may not be necessarily related to haemodialysis as the only illness.

Majority of the patients were elder 60 and above (70.7\%). In most studies patients were older compared with CAP patients $[9,10,11,12]$. The gender distribution was not statistically significant. Cough, dyspnoea and 
Original Research Article

fever were predominant pulmonary presentations and majority presented within 7 days; this was due to the severity of the presentation as evidenced by raised mean leukocyte count, procalcitonin level, renal and hepatic impairment. Bilateral lung lesions on radiography were also common features [13].

Many patients had multiple co-morbidities, majority having immunocompromised illness including COPD, diabetes mellitus and malignancy. They were having altered sensorium as extra pulmonary symptoms that could predispose them risk of aspiration. Similar observations were made by Carratala $\mathrm{J}$ et al [10].

Klebsiella spp, Acinetobacter, Pseudomonas and E. coli were notable gram-negative pathogens isolated from the clinical specimens. Pan drug resistance and extensive drug resistance were encountered among the Klebsiella spp, multidrug resistance among Acinetobacter and extensive drug resistance among Pseudomonas species respectively.

D'Agata EM found $0.55 \%-17 \%$ prevalence of infections caused by pathogens possessing extended -spectrum blactamases. Among the recent emergence of carbapenem - resistant Klebsiella species, three carbapenem hydrolysing beta-lactamase variants (KPC-1-KPC-3) have been reported $[14,15,16]$, these enzymes confer moderate to high level resistance to all agents in the carbapenem class.

Some of the plasmids that carry the genes responsible for carbapenem resistance also carry genes encoding extended - spectrum beta lactamases, in addition many of the isolates also carry determinants of resistance to aminoglycosides and are fluroquinolone resistant [17], thus making these strains resistant to multiple classes of antimicrobial agents.

Pathogens were isolated among 18 of 38 available cases; this could be due to viral etiology which were not evaluated. The real incidence of pathogenic causes could be underestimated [18].

Acinetobacter baumanni has emerged globally as an important pathogen in hospitalised patients, causing high morbidity and mortality. It can cause pneumonia, bacteraemia, meningitis, urinary tract infections and skin and soft tissue infections. This organism accounts for around $10 \%$ of all gram-negative isolate identified in Brooklyn, New York [19].

This spread of Gram- negative bacteria resistance to carbapenems is an urgent public threat and a critical priority according to World Health Organisation [20].
The variability of MDRO prevalence may be based on geographic location and patient population.

Thus, treatment choice should be guided by local microbial epidemiology. Our studies on microbial resistance are consistent with studies by Chalmers JD [21] and Aliberti S [22] et al.

Device Associated infections such as ventilatorassociated pneumonia, central line- associated blood stream infections, catheter-associated urinary tract infections and surgical-site infections account for most of the health care -associated infections that contributes to the growing antimicrobial resistance with resultant morbidity, mortality and adverse patient outcomes $[23$, $24,25]$.

Correlation of various parameters with outcome reveals elderly age, elevated leucocytosis, creatinine levels and bilateral consolidation on radiographs associated with increased mortality. CKD disrupts the internal metabolic milieu and hence is associated with many systemic abnormalities including cardiovascular, skeletal, haemopoietic, endocrine, nervous system, and also lungs. Greater awareness, thorough evaluation of all organs is essential to provide a better quality of life for the patient.

\section{Limitations of the study}

1. Small sample size.

2. Diagnostic samples could not be collected from all patients.

\section{Conclusion}

HCAP was witnessed in $58 \mathrm{CKD}$ cases with some having COPD, DM and malignancy as comorbid illnesses. Majority of patients were male, presented within a week of onset of symptoms of cough, dyspnoea, altered sensorium and also had increased leucocytes count and procalcitonin levels.

Non survivors had bilateral consolidation and increased leucocytosis. Klebsiella spp, Acinetobacter and Pseudomonas were important gram-negative resistant pathogens.

\section{What the study adds to the existing knowledge?}

Targeted antibiotic therapy is the key to managing such cases. Hospitals should adopt effective infection control measures to contain spread of multidrug resistance.

This study gives an insight into the epidemiology and prevalence of resistance pattern among organisms 
Original Research Article

causing HCAP in CKD patients in this part of the country.

However, further research involving a large number of patients from different institutions to corroborate the present findings regarding antibiotic resistance pattern of the microbes in HCAP cases is essential.

\section{Contributions from authors}

Dr. C. Mohan Rao: Conceived and designed the analysis, collected data.

Dr. Saswat Subhankar: Performed the analysis.

Dr. Aswini Prasad Patnaik: Contributed to the analysis.

Prof Debee Prasad Dash: Wrote the manuscript.

Findings: Nil; Conflict of Interest: None initiated Permission from IRB: Yes

\section{References}

1. Hill NR, Fatoba ST, Oke JL, Hirst JA, O'Callaghan CA, Lasserson DS, et al. Global Prevalence of Chronic Kidney Disease - A Systematic Review and MetaAnalysis. PLoS One. 2016;11 (7):e0158765. doi: 10. 1371 / journal.pone.0158765. eCollection 2016.

2. Ene-Iordache B, Perico N, Bikbov B, Carminati S, Remuzzi A, Perna A, et al. Chronic kidney disease and cardiovascular risk in six regions of the world (ISNKDDC): a cross-sectional study. Lancet Glob Health. 2016; 4(5):e307-19. doi: 10.1016/S2214-109X (16) 00071-1.

3. Guidelines for the Management of Adults with Hospital-acquired, Ventilator-associated, and Healthcare-associated Pneumonia. Am J Resp Crit Care Med. 2005;171(4):388-416. doi:https://doi.org/10.1164/ rccm. 200405-644ST

4. Spellberg B, Blaser M, Guidos RJ, Boucher HW, Bradley JS, Eisenstein BI, Combating Antimicrobial Resistance: Policy Recommendations to Save Lives. Clinic Infect Dis. 2011;52(suppl_5):S397-S428. doi: 10. $1093 / \operatorname{cid} / \operatorname{cir} 153$

5. Sievert DM, Ricks P, Edwards JR, Schneider A, Patel J, Srinivasan A, et al. Antimicrobial-resistant pathogens associated with healthcare-associated infections: summary of data reported to the National Healthcare Safety Network at the Centers for Disease Control and Prevention, 2009-2010. Infect Control Hosp Epidemiol. 2013;34(1):1-14. doi: 10.1086/668770. Epub 2012 Nov 27.
6. Rosón B, Carratalà J, Fernández-Sabé N, Tubau F, Manresa F, Gudiol F. Causes and factors associated with early failure in hospitalized patients with communityacquired pneumonia. Arch Intern Med. 2004;164(5):502-508. doi:10.1001/archinte.164.5. 502

7.Slinin Y, Foley RN, CollinsAJ. Clinical epidemiology of pneumonia in hemodialysis patients: the USRDS waves 1, 3, and 4 study. Kidney Int. 2006;70(6):11351141. Epub 2006 Jul 26. doi:10.1038/sj.ki.5001714

8. Guo H, Liu J, Collins AJ, Foley RN. Pneumonia in incident dialysis patients--the United States Renal Data System. Nephrol Dial Transplant. 2008;23(2):680-686. Epub 2007 Nov 19. doi:10.1093/ndt/gfm474

9. Shindo Y, Sato S, Maruyama E, Ohashi T, Ogawa M, Hashimoto N, et al. Health-care-associated pneumonia among hospitalized patients in a Japanese community hospital. Chest. 2009; 135(3):633-640.doi: 10.1378/ chest. 08-1357. Epub 2008 Nov 18.

10. Carratalà J, Mykietiuk A, Fernández-Sabé N, Suárez C, Dorca J, Verdaguer R, Manresa F, et al. Health careassociated pneumonia requiring hospital admission: epidemiology, antibiotic therapy, and clinical outcomes. Arch Intern Med. 2007;167(13):1393-1399. doi:10. $1001 /$ archinte. 167.13.1393.

11. Micek ST, Kollef KE, Reichley RM, Roubinian N, Kollef MH. Health care-associated pneumonia and community-acquired pneumonia: a single-center experience. Antimicrobial agents and chemotherapy. 2007;51(10):3568-3573. doi: 10.1128/AAC.00851-07

12. Falcone $\mathrm{M}$, Venditti $\mathrm{M}$, Shindo $\mathrm{Y}$, Kollef $\mathrm{MH}$. Healthcare-associated pneumonia: diagnostic criteria and distinction from community-acquired pneumonia. Int J Infect Dis. 2011;15(8):e545-550. doi: 10.1016/j. ijid.2011.04.005. Epub 2011 May 26.

13. Venditti M, Falcone M, Corrao S, Licata G, Serra P; Study Group of the Italian Society of Internal Medicine. Outcomes of patients hospitalized with communityacquired, health care-associated, and hospital-acquired pneumonia. Ann Intern Med. 2009;150(1):19-26. doi:10.7326/0003-4819-150-1-200901060-00005

14. Yigit H, Queenan AM, Anderson GJ, DomenechSanchez A, Biddle JW, Steward CD, Alberti S, Bush K, Tenover FC.Novel carbapenem-hydrolyzing $\beta$ lactamase, KPC-1, from a carbapenem-resistant strain of Klebsiella pneumoniae. Antimicrob Agents Chemo. 2001; 45(4):1151-1161. doi: 10.1128/AAC.45.4.11511161.2001

Pathology Update: Tropical Journal of Pathology \& Microbiology Available online at: www.medresearch.in 654 | P a g e 


\section{Original Research Article}

15. Hossain A, Ferraro MJ, Pino R, Dew RB, Moland ES, Lockhart TJ, Thomson KS, Goering RV, Hanson ND.Plasmid-mediated carbapenem-hydrolyzing enzyme KPC-2 in an Enterobacter sp. Antimicrob Agents Chemo.2004; 48(11): 4438-4440.doi: 10.1128/AAC. 48. 11. 4438-4440.2004

16. van Duin D, Doi Y. The global epidemiology of carbapenemase- producing Enterobacteriaceae. Virulence. 2017;8(4): 460-469. doi: 10.1080/21505594. 2016. 1222343. Epub 2016 Aug 11.

17. Quale JM, Landman D, Bradford PA, Visalli M, Ravishankar J, Flores C, et al. Molecular epidemiology of a citywide outbreak of extended-spectrum betalactamase-producing Klebsiella pneumoniae infection. Clin Infect Dis. 2002;35(7):834-841. Epub 2002 Sep 10. doi: $10.1086 / 342577$

18. Kollef MH, Shorr A, Tabak YP, Gupta V, Liu LZ, Johannes RS. Epidemiology and outcomes of healthcare-associated pneumonia: results from a large US database of culture-positive pneumonia. Chest. 2005;128(6): 3854-3862. doi:10. 1378/ chest. 128.6. 3854

19. Manikal VM, Landman D, Saurina G, Oydna E, Lal H, QualeJ.Endemic carbapenem-resistant Acinetobacter species in Brooklyn, New York: citywide prevalence, interinstitutional spread, and relation to antibiotic usage. Clin Infect Dis. 2000 ;31(1):101-106. Epub 2000 Jul 17. doi: $10.1086 / 313902$

20. Shrivastava SR, Shrivastava PS, Ramasamy J. World health organization releases global priority list of antibiotic-resistant bacteria to guide research, discovery,

and development of new antibiotics. J Med Soc. 2018;32(1):76-77. doi: 10.4103/jms.jms_25_17

21.Chalmers JD, Taylor JK, Singanayagam A, Fleming GB, Akram AR, Mandal P, et al. Epidemiology, antibiotic therapy, and clinical outcomes in health careassociated pneumonia: a UK cohort study. Clin Infect Dis. 2011;53(2):107-113. doi: 10.1093/cid/cir274.

22. Aliberti S, Di Pasquale M, Zanaboni AM, Cosentini $\mathrm{R}$, Brambilla AM, Seghezzi S, et al. Stratifying risk factors for multidrug-resistant pathogens in hospitalized patients coming from the community with pneumonia. Clin Infect Dis. 2012;54(4):470-478. doi: 10.1093/cid/ cir 840. Epub 2011 Nov 21.

23. Durlach R, McIlvenny G, Newcombe RG, Reid G, Doherty L, Freuler C, et al. Prevalence survey of healthcare-associated infections in Argentina; comparison with England, Wales, Northern Ireland and South Africa. J Hosp Infect. 2012;80(3):217-223. doi: 10. 1016/j.jhin.2011.12.001. Epub 2012 Jan 9.

24. Salgado Yepez E, Bovera MM, Rosenthal VD1, González Flores HA, Pazmiño L, Valencia F, et al. Device-associated infection rates, mortality, length of stay and bacterial resistance in intensive care units in Ecuador: International Nosocomial Infection Control Consortium's findings. World J Biol Chem. 2017;8 (1): 95-101. doi: 10.4331/wjbc.v8.i1.95.

25. KDIGO 2017 Clinical Practice Guideline Update for the Diagnosis, Evaluation, Prevention, and Treatment of Chronic Kidney Disease-Mineral and Bone Disorder (CKD-MBD). (2017). Kidney International Supplements, 7(1), pp.1-59.

\section{How to cite this article?}

Rao C.M, Subhankar S, Patnaik A.P, Dash D.P. Clinical and microbiological profile of health care associated pneumonia in patients with chronic renal disease referred to a tertiary care hospital- a prospective study. Trop J Path Micro 2019; 5(9):648-655.doi:10.17511/jopm.2019.i09.06. 